\title{
Construction of the Tuen Mun-Chek Lap Kok Link Sub-sea Tunnels in Hong Kong
}

\author{
A W Y Chan ${ }^{1}$, Charles H C Yeung ${ }^{2}$, A J Westmoreland ${ }^{2}, \mathrm{~S} \mathrm{~W} \mathrm{Fok}{ }^{2}, \mathrm{C} \mathrm{C} \mathrm{W} \mathrm{Ng}{ }^{2}$ and F Guedon ${ }^{3}$ \\ ${ }^{1}$ Highways Department, the HKSAR Government, Hong Kong, People's Republic of China \\ ${ }^{2}$ AECOM Asia Company Limited, Hong Kong, People's Republic of China \\ ${ }^{3}$ Dragages-Bouygues JV, Dragages Hong Kong Limited, Hong Kong, People's Republic of China
}

\begin{abstract}
The entire Tuen Mun-Chek Lap Kok Link (TM-CLKL) was commissioned on 27 December 2020 and comprises a 9 km dual twolane carriageway between Tuen Mun and North Lantau, Hong Kong. The challenges for the construction of the TM-CLKL tunnels included sub-sea tunnelling up to $55 \mathrm{~m}$ below sea level in mixed ground geology that required replacement of tunnel boring machine (TBM) cutting tools at hyperbaric pressure up to 5.8 bars; replacement of worn TBM cutting tools in complicated ground conditions; construction of approach tunnels in newly reclaimed land subject to long-term consolidation; and construction of cross passages at 100-metre intervals between the two sub-sea tunnels with a risk of sea water ingress at 5.5 bars. This project has deployed sophisticated techniques to surmount the challenges encountered during construction of the five-kilometre-long sub-sea tunnels. These included the use of the world's largest slurry-type Mixshield TBM, $17.63 \mathrm{~m}$ in diameter, for the construction of the northern approach tunnel, followed by two $14 \mathrm{~m}$ diameter slurry-type Mixshield TBMs for the construction of the sub-sea tunnels; use of saturation diving techniques for TBM cutterhead interventions up to 5.8 bars which was the first such works in Hong Kong and one of only a few uses of saturation diving in tunnelling worldwide; use of ground freezing techniques in complicated ground conditions for TBM interventions to change worn cutting tools at the TBM cutterhead; TBM tunnelling in newly reclaimed land at the northern landfall and the southern landfall; and the construction of cross passages by mini-TBM using pipe jacking methods between the two main tunnel tubes which was the first such works ever undertaken anywhere in the world. This paper introduces the successful implementation of these techniques for the satisfactory completion of the TM-CLKL sub-sea tunnels.
\end{abstract}

KEYWORDS Civil Engineering; Geotechnical Engineering; Tunnelling

CONTACT C HC Yeung sret2cyg@trunkroadt2.com

Received 21 October 2019

\section{Introduction}

The entire Tuen Mun-Chek Lap Kok Link (TMCLKL) was commissioned on 27 December 2020 and comprises a $9 \mathrm{~km}$ dual two-lane carriageway between Tuen Mun and North Lantau, Hong Kong (Figure 1). The alignment commences at the Lung Mun Road and Lung Fu Road Roundabout in Tuen Mun Area 46. It heads southeast on an elevated structure over Lung Mun Road and lands on a new reclamation (referred to as the northern landfall (NLF)) adjacent to the Tuen Mun River Trade Terminal (RTT). The alignment turns south and heads into a $5 \mathrm{~km}$ sub-sea tunnel passing under the Urmston Road, a busy navigation channel between Lantau Island and Tuen Mun. After crossing the Urmston Road, the alignment daylights at the eastern edge of the reclaimed Hong Kong-ZhuhaiMacao Bridge Hong Kong Port (HZMB HK Port) near the Hong Kong International Airport at Chek Lap Kok (referred to as the southern landfall (SLF)) and then head eastwards on a marine viaduct to connect with the North Lantau Highway at Tai Ho Wan of Lantau.

Construction of the $650 \mathrm{~m}$ northern approach tunnels was carried out using a 17.63 m diameter TBM, the world's largest slurry-type Mixshield TBM, for the northbound tunnel and a $14 \mathrm{~m}$ diameter TBM for the southbound tunnel. The $4.2 \mathrm{~km}$ sub-sea tunnel section across the busy Urmston Road shipping channel between the HZMB HK Port and Tuen Mun was constructed using two 14 $\mathrm{m}$ diameter TBMs. The adoption of TBM for sub-sea tunnel construction completely avoided any impact on the Urmston Road marine traffic during construction and minimised the impact to the marine habitat of the Chinese White Dolphins within and near the work site of the project.

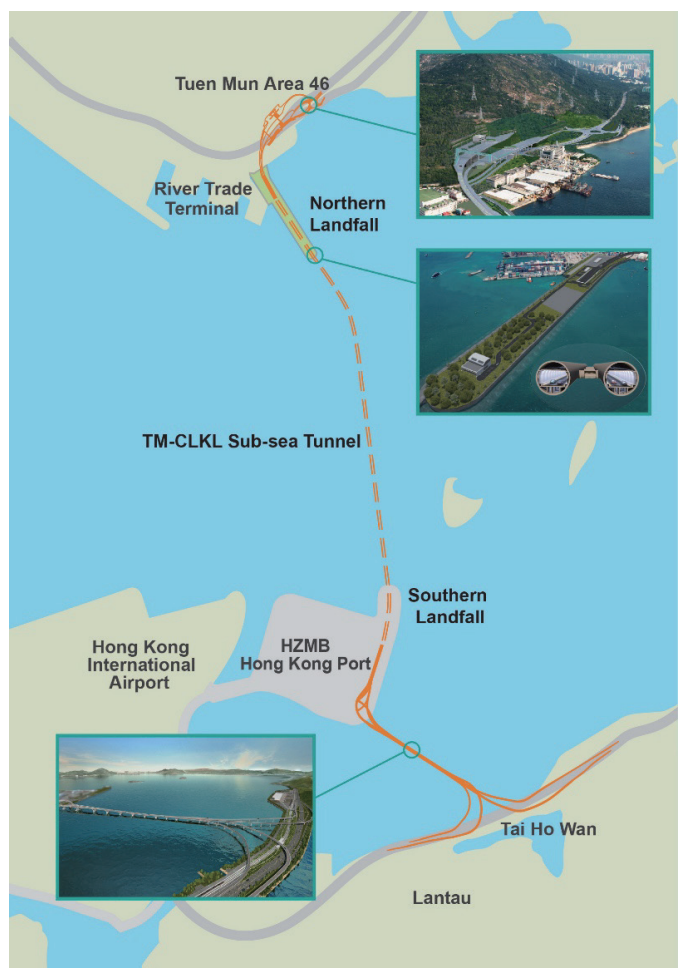

Figure 1. General view of TM-CLKL alignment (Chan el at., 2021: p.31). 
This paper aims at introducing the various sophisticated techniques deployed to surmount the challenges encountered during the construction of the TMCLKL sub-sea tunnels.

\section{Geology of the TM-CLKL Sub-Sea Tunnels}

The vertical tunnel alignment for the TM-CLKL subsea tunnel section was designed to avoid any impact on existing structures, marine traffic using the Urmston Road shipping channel, and existing electric power submarine cables, and to minimise the impact to the marine ecological habitat (Figure 2).

At the NLF between the TBM launching shaft (LS) and the north ventilation shaft (NVS), the tunnel mainly encountered mixed ground conditions which were comprised of reclamation fill, vibro-compacted sand, marine deposits, alluvial sand, alluvial clay and granite.

In the sub-sea tunnel section between the NVS and the south ventilation shaft (SVS), the tunnel was in mixed ground conditions with the first $500 \mathrm{~m}$ in mixed geology of slightly-tomoderately decomposed granite and completely decomposed granite (CDG), followed by soft ground conditions with CDG, alluvial sand, alluvial clay and marine deposits.

At the SLF, the tunnel mainly encountered mixed ground conditions comprising alluvial sand, alluvial clay and metasediments.

\section{TBM tunnelling}

\subsection{TBMfeatures}

Three slurry-type Mixshield TBMs supplied by Herrenknecht, named as S880, S881 and S882, were deployed to construct the tunnels. They were designed to be capable of tunnelling through hard rock, but also capable of excavating and supporting soft ground within acceptable ground loss limits. The TBMs allowed for the construction of precast segmental lining as immediate permanent ground support just behind the TBM shields.

There were a number of special features adopted in the Tuen Mun-Chek Lap Kok Link (TM-CLKL) TBM which are listed below (Figure 3):

- TBMs previously deployed in Hong Kong projects were for the construction of cable tunnels, drainage tunnels or mass transit tunnels with diameters less than $10 \mathrm{~m}$. The TBMs proposed for the road tunnels in TM-CLKL were larger than any previously used before in Hong Kong and the $17.63 \mathrm{~m}$ diameter TBM (S880) was the largest TBM ever manufactured in the world when it was launched in 2015 (Tracking the world's megaTBMs, 2020);

- Mobydic - a predictive monitoring system was installed on some of the cutters to monitor both geological conditions and cutterhead operation and wear (Figure 4);
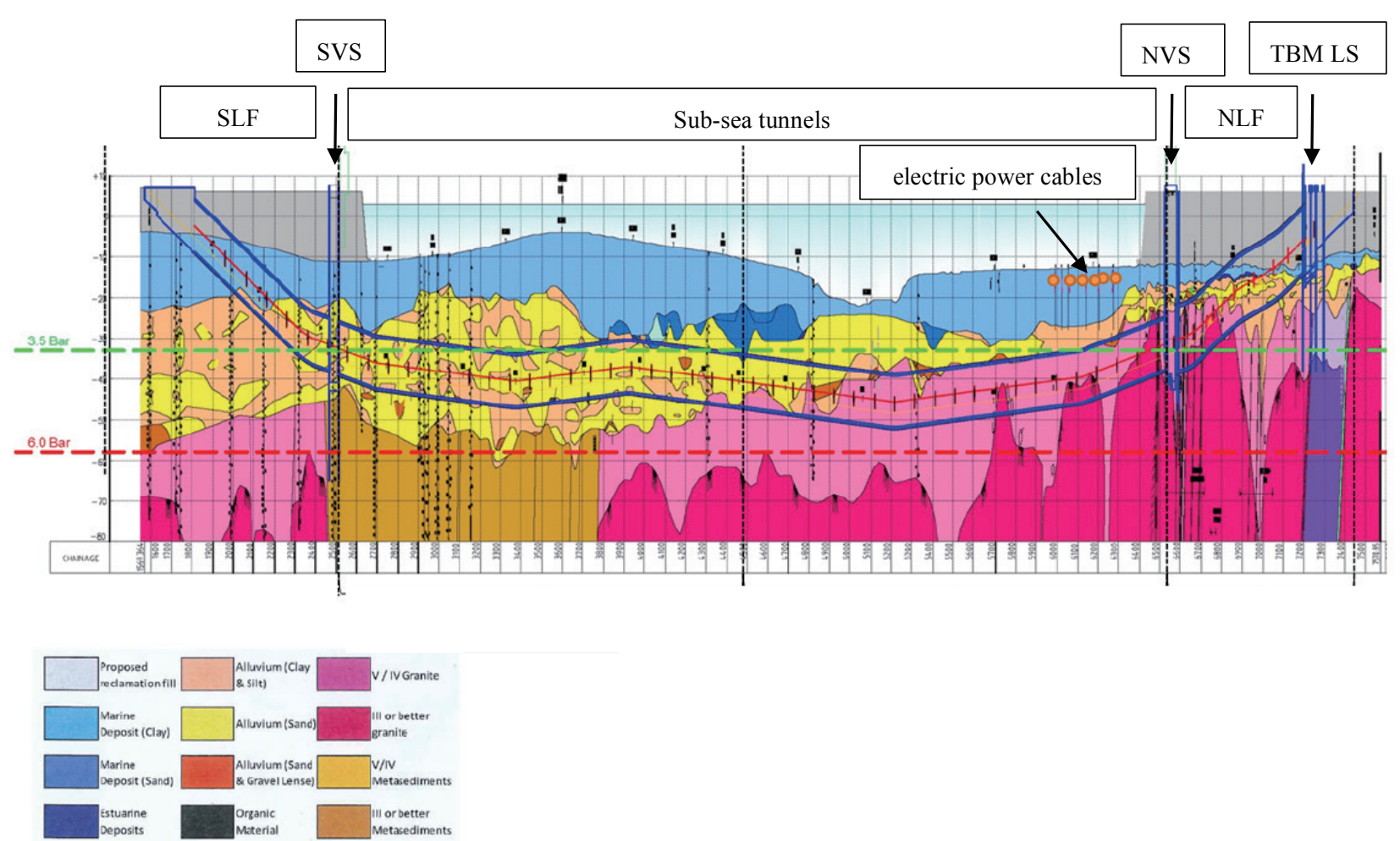

Figure 2. Geological profile of the TM-CLKL sub-sea tunnels. 


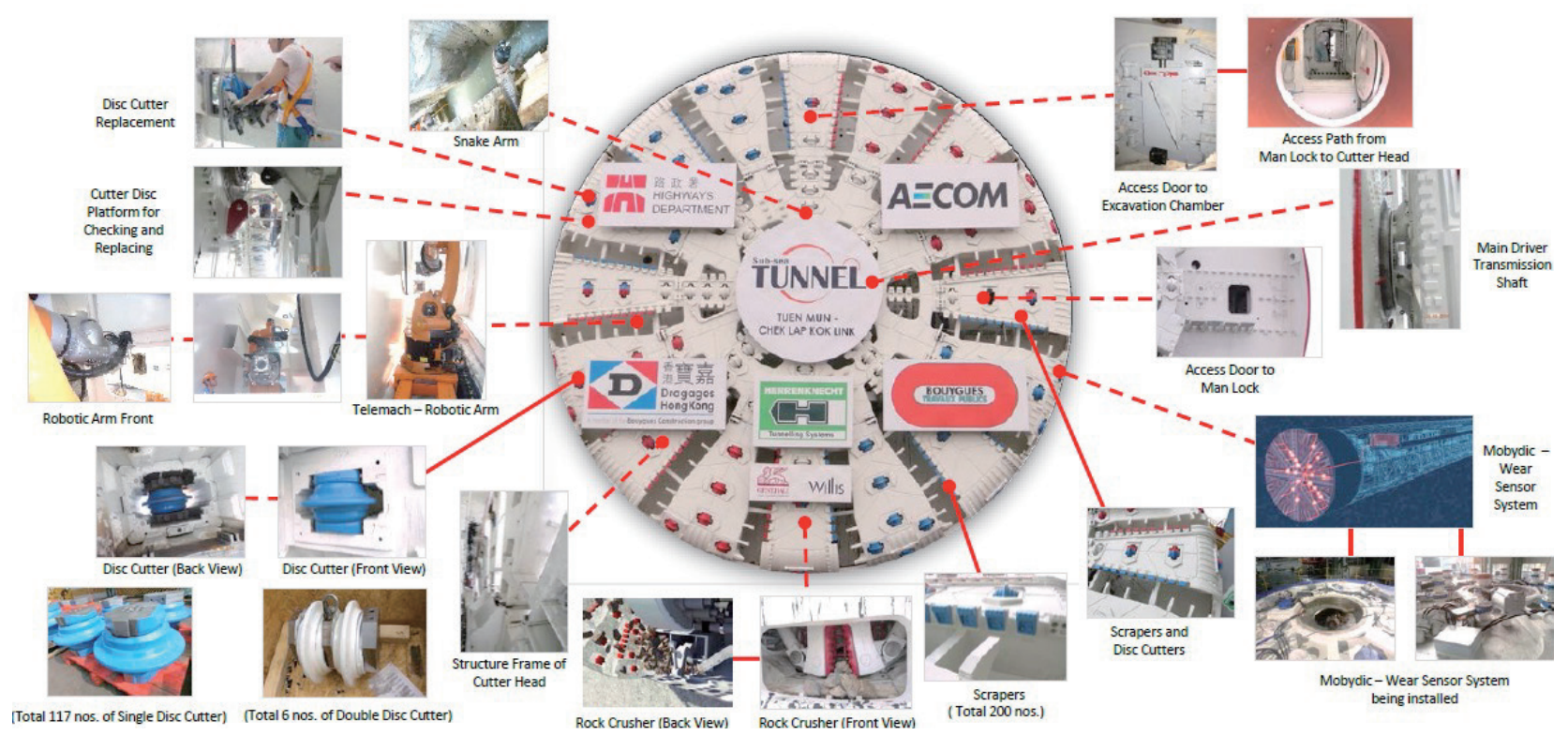

Figure 3. TBM features.

- Snake - a remotely operated endoscopic inspection device that allowed inspection of the tunnel face and the cutterhead without the need for manned interventions (Figure 5);

- Telemach - a robotic arm for the remote replacement of worn TBM cutters without the need for manned interventions (Figure 6);

- Disc cutters - 19-inch disc cutters with a tailor made housing to enable change of cutters using Telemach;

- Hyperbaric shuttle handling - the TBMs were designed to allow saturation intervention to be conducted, with the capability to handle and transport the pressurised hyperbaric shuttle chamber through the gantries, and a scissor-lift platform in the shield to lift the shuttle to the TBM man-lock for connection and transfer;

- Compressed air locks - two man-locks were provided for each TBM. Both man-locks contained a two-chamber/three-door system. One man-lock was designed with a circular NATO flange to enable shuttle connection and transfer during saturation intervention operations;

- Chilling system for the intermediate chamber water and air chilling systems were provided in the intermediate chamber of the TBM shield to chill air bubbles and provide an improved working environment for cutterhead interventions;

- Refuge chamber - in each TBM a refuge chamber was provided to provide emergency refuge for up to 25 people for a duration of 30 hours;
- Stone crusher - the TBMs were equipped with a hydraulic jaw type crusher capable of crushing rocks or boulders up to a size of $1.2 \mathrm{~m}$; and

- No shield articulation - the tailskin was welded to the rear of the shield without shield articulation. As the curve radius for horizontal/vertical alignment for the TM-CLKL sub-sea tunnel was not tight, the TBMs could use the spherical bearing of the main drive to negotiate a curve.

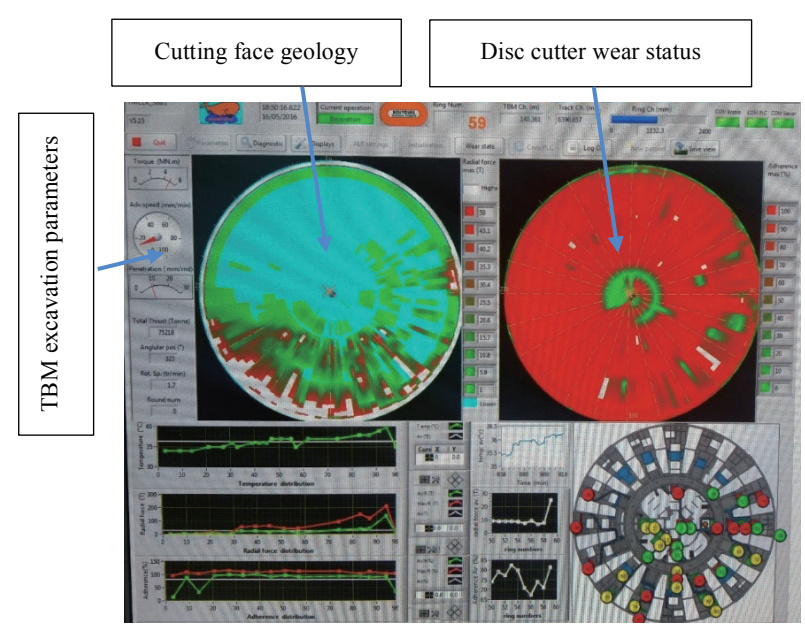

Figure 4. Mobydic. 


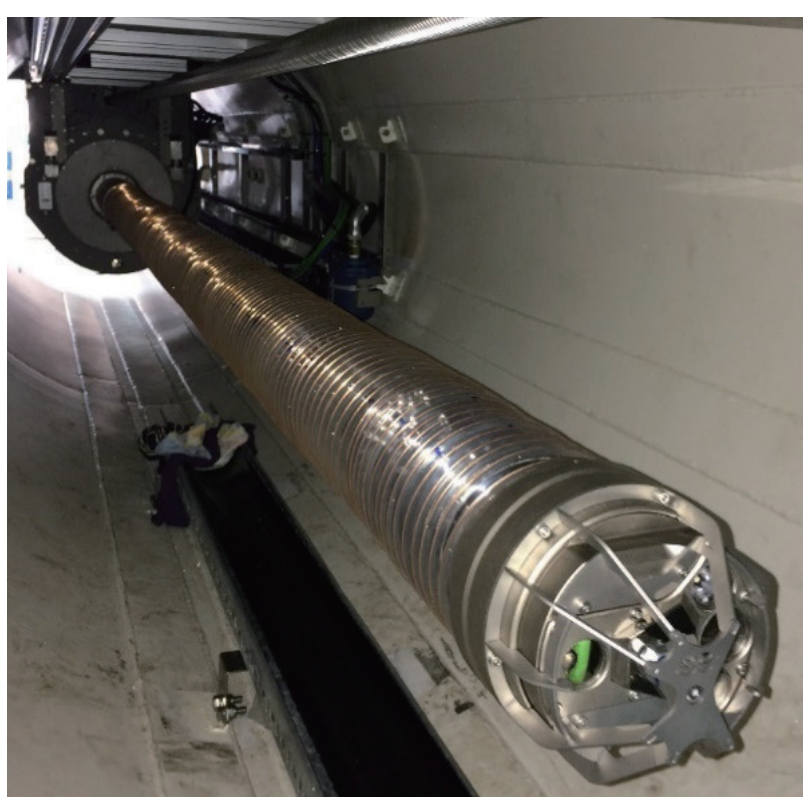

Figure 5. Snake.

(a)

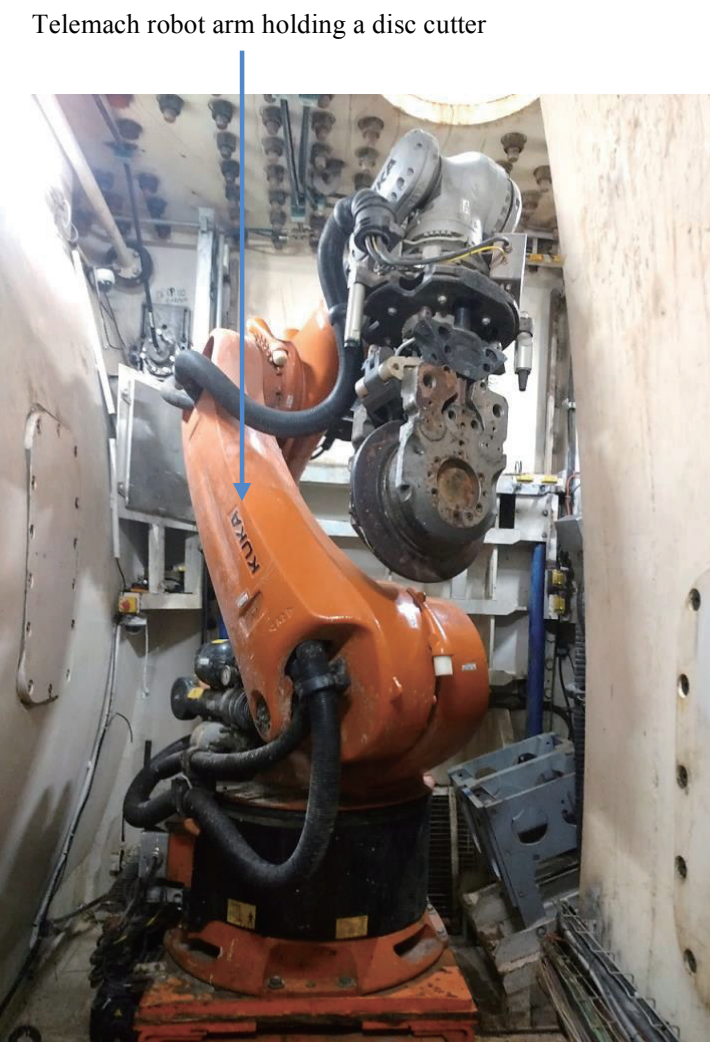

(b)

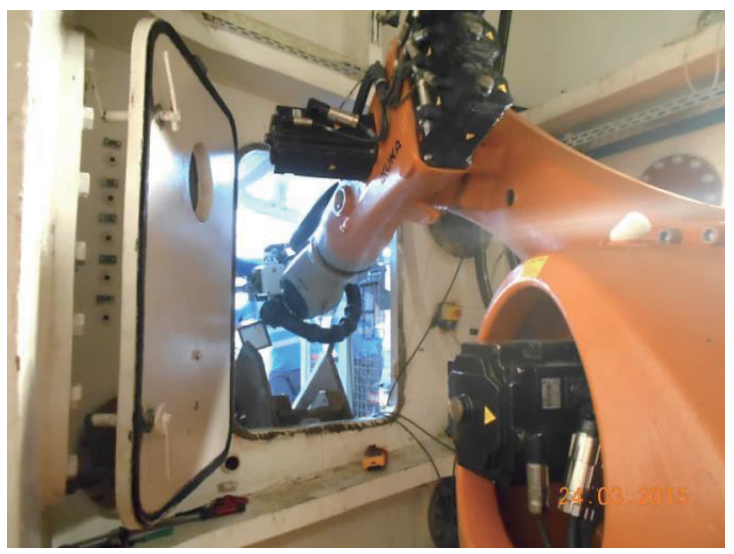

(c)

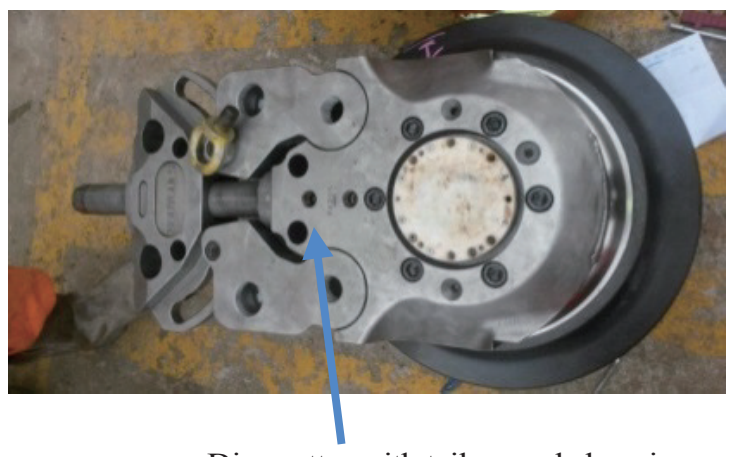

Disc cutter with tailor-made housing

Figure 6(a) to (c). Telemach replacing a new 19-inch disc cutter mounted with a tailor-made housing.

The slurry treatment plant (STP) is a major component of a slurry-type TBM. For the TM-CLKL sub-sea tunnel project, two STPs, each having the capacity to handle incoming flow of 3,200 $\mathrm{m} 3 /$ hour were deployed. The general operation of the STP falls into three main functions which are spoil separation, slurry management and mud dehydration, as shown in Figure 7. Spoil separation is the general term for the process designed to extract the solids (TBM spoil) from the slurry. It is achieved in three steps including scalping, de-sanding and de-silting. Slurry management is the general term for the process designed to control the slurry density and rheological properties. The equipment necessary for spoil management includes a series of storage tanks and valves for storage and supplementation of the slurry with water, fresh bentonite or other chemicals; further treatment will be carried out using the centrifuges with flocculation, and/or electrolyte chemicals will be added into the treatment as required. The mud dehydration process involves the addition of lime to the mud, which is then pressed as it is circulated through the series of filter-presses which squeeze the mud between plates to form a cake of the fine spoil material, allowing the water to be squeezed off. When the cakes are sufficiently dense, they are released to the muck bin and the cycle is repeated. The TBM spoil and mud cake were disposed of by barges to the local public fills or cross-border receptor sites for reclamation. 


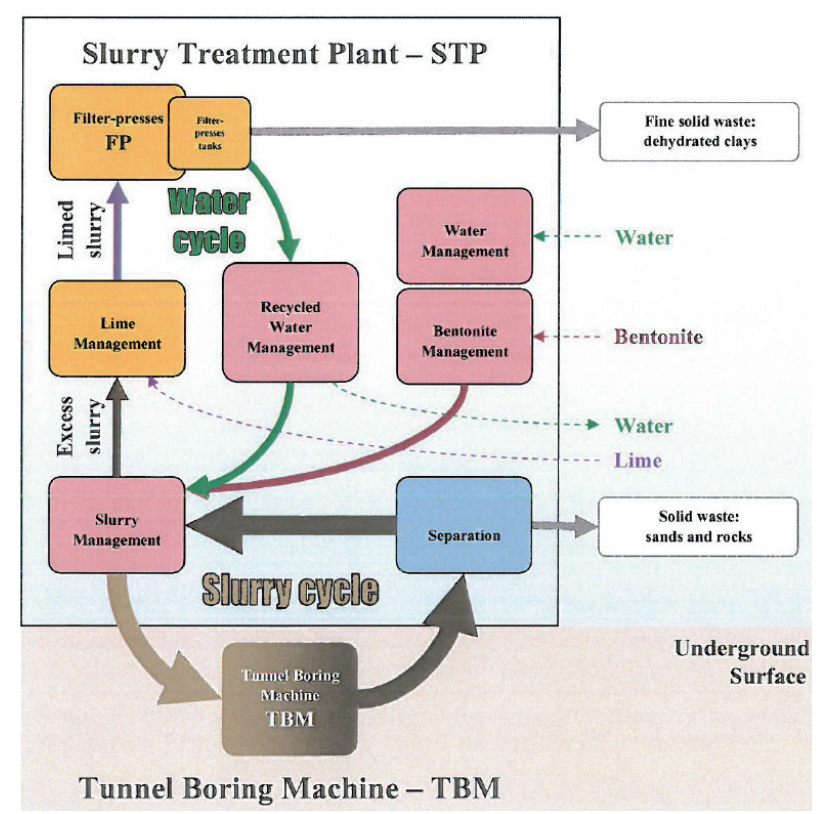

Figure 7. General process of a STP.

\subsection{TBM launching and changing diameter}

The first TBM (S880), a $17.63 \mathrm{~m}$ diameter Mixshield, drove $650 \mathrm{~m}$ of the northbound tunnel from the LS to the NVS at the NLF where the shield of TBM (S880) was dismantled and replaced inside the NVS by a $14 \mathrm{~m}$ diameter Mixshield TBM (S881). TBM (S881) then launched from the NVS and drove to the SLF for the construction of the northbound sub-sea tunnel. Another $14 \mathrm{~m}$ diameter Mixshield TBM (S882) drove from the LS of the NLF, through the NVS, to the SLF for the construction of the southbound tunnel (Figure 8).

Prior to excavation of the tunnels, a peanut-shaped TBM LS, approximately $100 \mathrm{~m}$ long and $50 \mathrm{~m}$ wide, was constructed using a "caterpillar" diaphragm wall especially designed for the TBM launch at the NLF. This LS was formed by constructing consecutive reinforced concrete retaining wall panels and foundations for the future permanent cut-and-cover tunnel box structure. The circular diaphragm walls resisted earth and water pressures through a combination of bending and hoop stresses mobilised in the circular diaphragm walls. Lateral support was provided by two flying beams and cross-walls between the intersecting circular cells. This structure also supported the gantry crane with a lifting capacity of 560 tons running on the flying beams (Figure 9).

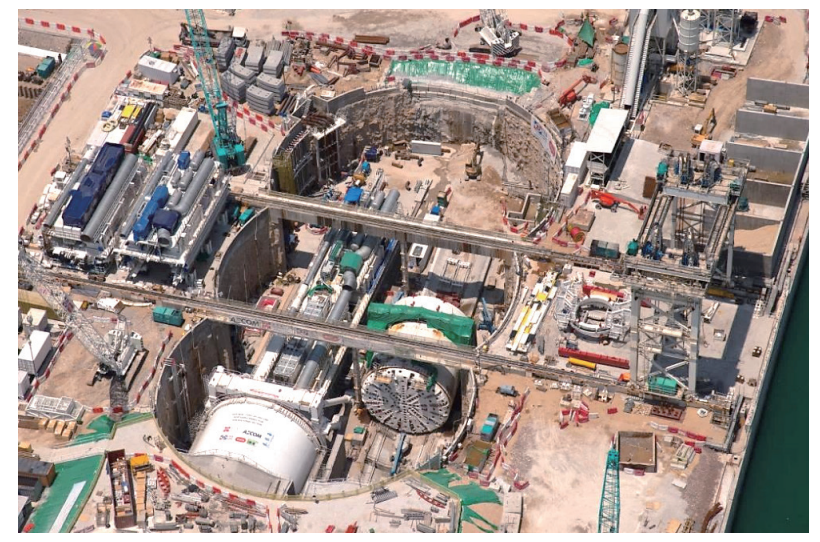

Figure 9. TBMs (S880) and (S882) assembly in the peanutshaped LS.

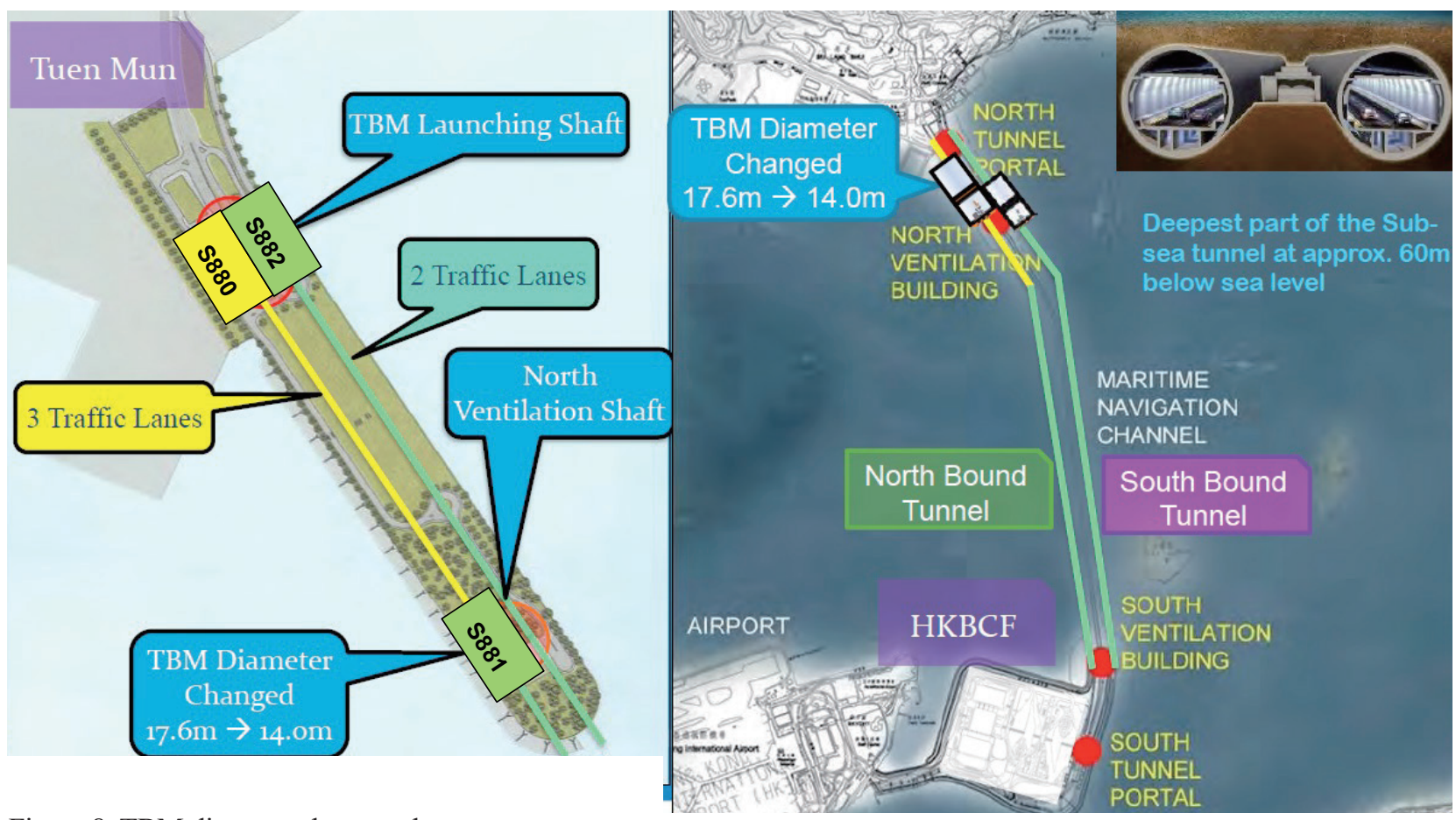

Figure 8. TBM diameter change scheme. 
The TBM (S880) shield and the first two gantries were initially assembled inside the LS from where it progressively excavated forward, with the rear two gantries lowered down the shaft and assembled in stages. TBM (S882) was assembled in a similar sequence following TBM (S880).

After launch, TBM (S880) excavated $650 \mathrm{~m}$ to complete the northbound tube of the northern approach tunnel and break-out into the NVS to change its diameter from $17.63 \mathrm{~m}$ to $14 \mathrm{~m}$ (Figure 10). TBM (S882) was launched a couple of months after the launch of TBM (S880) and completed the southbound tube of the northern approach tunnel. While TBM (S880) was changing its diameter to TBM (S881), TBM (S882) overtook TBM (S881) to continue tunnelling across the NVS inside a steel bell installed at the bottom of the shaft (Figure 11).

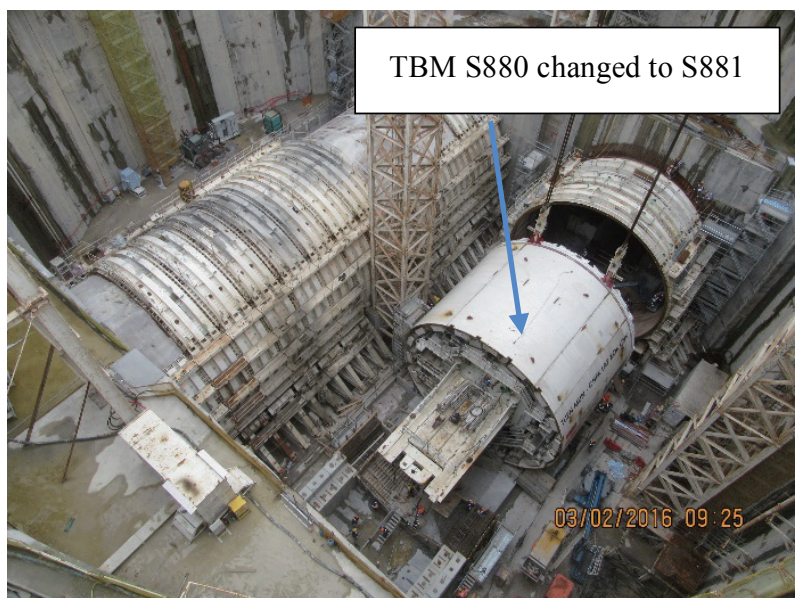

Figure 10. TBM (S880) changing diameter to TBM (S881).

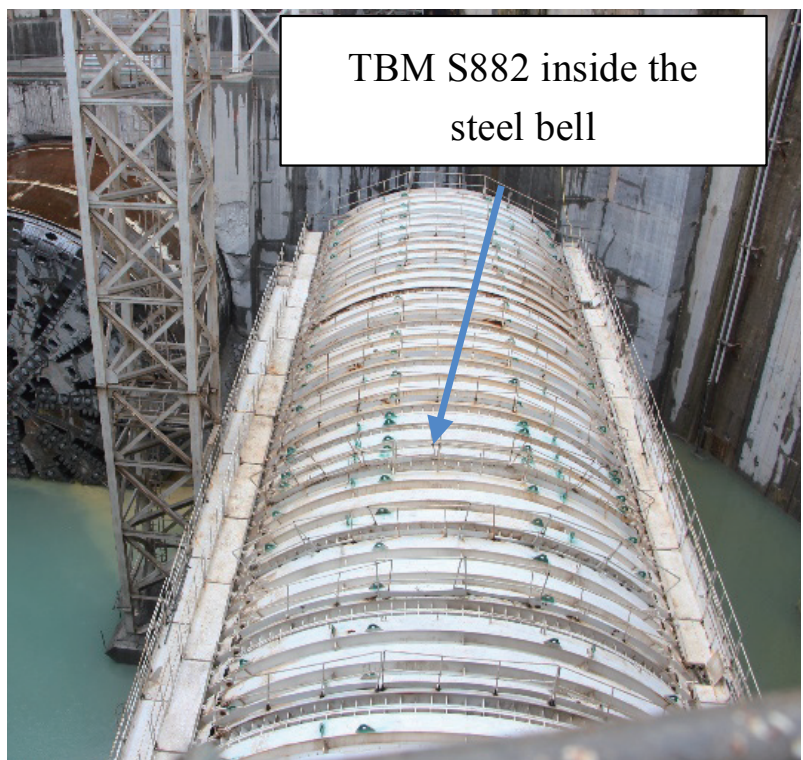

Figure 11. Steel bell inside NVS for the transit of TBM (S882).

\subsection{TBM interventions using saturation diving techniques}

The maintenance of the TBM cutterhead required regular inspections to monitor wear of the cutter tools, replace worn tools and undertake any repairs necessary to the cutterhead itself, in order to prevent the TBM from becoming stuck underground.

The TBMs in the TM-CLKL project were equipped with special equipment to optimise the efficiency of the TBM interventions. Mobydic (Figure 4) was a predictive monitoring system that was installed on some of the cutters to monitor both geological conditions and cutterhead operation and cutter wear. If cutter wear was detected by Mobydic, then a remotely operated endoscopic inspection device called the Snake (Figure 5) would be deployed to inspect the tunnel face and the cutterhead without the need for manned inspection under a hyperbaric environment. Once cutter wear was confirmed and disc replacement was required, the Telemach (Figure 6) - a robotic arm for the remote replacement of worn TBM cutters - would be deployed to change the cutters without the need for manned interventions. For those worn disc cutters that could not be successfully replaced by the Telemach, manned interventions would be carried out.

During the manned interventions, compressed air was used to balance the hydrostatic and earth pressures, creating a hyperbaric environment within the excavation chamber of the TBM.

Failure to balance the groundwater pressure would lead to face instability due to the flow of water from the ground into the void created by the TBM excavation. Water flow from the face could result in ground material being washed into the excavation chamber during compressed air works, causing face collapse, with a subsequent ground surface settlement or, in more serious incidents, a sinkhole at the ground surface above the TBM.

As the tunnel depth was up to $55 \mathrm{~m}$ below sea level with the deepest seabed level at $-21 \mathrm{mPD}$, the intervention pressure could be up to 6 bar, as shown in Figure 2 . According to the Factories and Industrial Undertakings CAP59M (Work in Compressed Air) Regulations, no person shall be employed in compressed air at a pressure exceeding 3.45 bar without permission from the Commissioner for Labour. In this connection, exemption from Labour Department was required to carry out hyperbaric works above 3.45 bar.

Intervention with compressed air under high pressure poses occupational safety and health $(\mathrm{OSH})$ risks to the hyperbaric workers due to its narcosis effects and the high dosage of oxygen resulting in oxygen toxicity. In traditional bounce hyperbaric works, the risk of having decompression illness (DCI) is high due to frequent compression and decompression at the start and end of each intervention. To minimise the OSH and DCI risk for the hyperbaric workers, the project consultant, AECOM, introduced the concept of saturation diving techniques as the TBM cutterhead intervention strategy during the project 
design stage. AECOM specified provisions for saturation diving techniques in the employer's requirements in the contract, which required the contractor to provide saturation diving equipment and facilities and design the TBM to allow the use of saturation diving techniques for TBM cutterhead interventions if needed. The use of saturation diving techniques for TBM cutterhead interventions had previously been deployed by only a few tunnel projects around the world, and TM-CLKL was the first to use these techniques in Hong Kong.

In the TM-CLKL project, three modes of hyperbaric works were deployed. These three modes were air mode (from 0 bar to 4.2 bar), trimix bounce mode (from 3.45 bar to 5.5 bar) and saturation mode (from 3.45 bar to 6 bar). Under trimix bounce mode and saturation mode, the hyperbaric workers breathe trimix gas comprising oxygen, nitrogen and helium instead of normal air.

Under air mode or trimix bounce mode, the intervention team was compressed to the required pressure in the TBM man-lock. Once pressure equalisation was completed between the man-lock, the air bubble and the excavation chamber, and when the required air quality had been checked, the team entered to the cutterhead to carry out the inspection/maintenance works. The intervention team would go back into the man-lock for decompression when they had completed their task, or prior to reaching the maximum working time stipulated in the working tables, a duration that could be as short as 45 minutes in pressures approaching 5 bar.

Under saturation mode, the hyperbaric workers were saturated and stayed under pressure in a living chamber, which was located inside a living habitat compound on the surface, for a period of up to 28 days, including three days of decompression. When TBM intervention was required, these workers were transferred under pressure (TUP) by means of a TUP shuttle travelling from the living habitat on the surface to the underground TBM where the shuttle was connected to the man-lock. The saturation workers could work inside the excavation chamber for up to six hours with a 30-minute meal break. After six hours, the saturation workers were transferred back to the living chamber by means of the TUP shuttle, whilst staying in a hyperbaric environment the whole time.

\subsection{Precast segmental lining and tunnel internal structures}

The TBM tunnels were lined with pre-cast universal concrete segmental lining designed as an undrained lining with a design life of up to 120 years. The design life generally refers to a life without replacement of any major components, with maintenance and some repair for its achievement. This comprises a durability assessment by means of protection (by durability design) and mitigation (by maintenance) in order to ensure the design life of 120 years can be achieved with a good degree of confidence. Structural and deformation checking on the precast segmental lining were carried out to ensure the structural stability and deformation of the lining. The structural capacity was checked in compliance with the Code of Practice for Structural Use of Concrete 2004 and the crack width of the lining was controlled to be not more than 0.2 $\mathrm{mm}$ in order to achieve the durability requirement. In the durability assessment of the segmental lining, the exposure classification was made reference to the Structures Design Manual for Highways and Railways 2006 with a design life of 120 years. In addition, the tunnel segmental lining was designed to withstand a maximum $1 \%$ tunnel ovalisation. The joint opening associated with the maximum allowable deformation and the minimum hoop load was calculated to verify the suitability of the proposed gasket. The proposed gasket was capable of resisting 10 bar of pressure with a gap opening of less than $4 \mathrm{~mm}$.

The northern approach tunnels have internal diameters of $12.4 \mathrm{~m}$ and $15.6 \mathrm{~m}$ with excavated diameters of $14 \mathrm{~m}$ and $17.6 \mathrm{~m}$. The sub-sea tunnels and southern approach tunnels have an internal diameter of $12.4 \mathrm{~m}$ with excavated diameter of $14 \mathrm{~m}$. The lining segments are grade 55/20 concrete, $550 \mathrm{~mm}$ thick for the tunnel internal diameter of $12.4 \mathrm{~m}$ and $700 \mathrm{~mm}$ thick for the tunnel internal diameter of $15.6 \mathrm{~m}$.

The tunnels of TM-CLKL were made up of nine (S881/ S882) or twelve (S880) precast concrete segments which were sequentially assembled to form a ring. For S880, i.e. $15.6 \mathrm{~m} \mathrm{ID}$, these were known as $\mathrm{S} 1$ to $\mathrm{S} 9$ (standard segments), S10 and S11 (counter key segments), and K12 (key segment). For S881 and S882, i.e. $12.4 \mathrm{~m} \mathrm{ID,} \mathrm{these}$ were known as S1 to S6 (standard segments), S7 and S8 (counter key segments), and K9 (key segment) (Figure 12). The segmental ring was tapered on both the leading and trailing edges to suit the horizontal and vertical curves of the tunnel alignment.

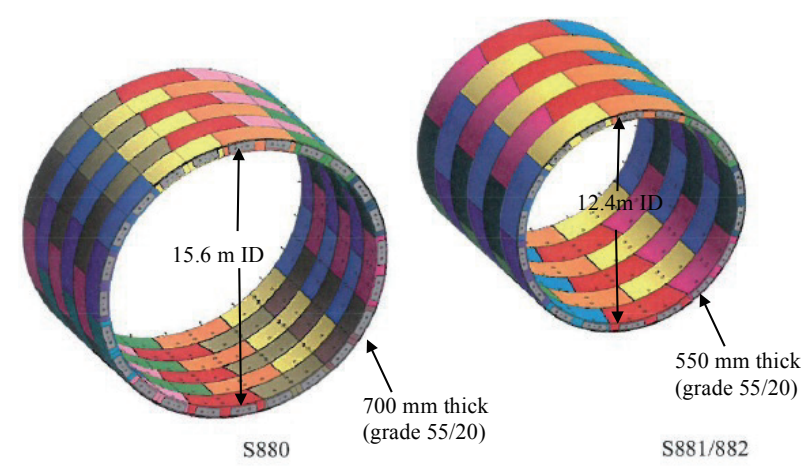

Figure 12. Typical cross section of segmental lining.

Special segments, with increased quantity of reinforcement and a fibre-glass reinforced soft eye, were adopted for the construction of the mechanised cross passages to resist the temporary and permanent loads around the cross passage opening and allow the cross passage mini-TBM to excavate through the reinforced concrete of the main tunnel lining. 
Each segment was fitted with a hydrophilic and ethylene propylene diene monomer (EPDM) compressible gasket which was installed between the circumferential faces of the segmental lining to achieve the full watertightness requirements of the specification and assist in distributing machine or shield thrust forces through the lining.

As each segmental ring is universal, there are 24 (for S880) or 18 (for S881/S882) possible positions in which the key segment could be located, with positions corresponding directly to the thrust ram number. The key location was determined by the contractor's in-house Pyxis guidance system, which combined all measurements and values to predict the key position of the next three rings.

For straight sections of the tunnel alignment, the ring was installed with the key in alternating positions, i.e. if the key of "Ring A" was installed on the left, the subsequent "Ring B" would have the key on the right. For curved sections of tunnel alignment, segment $\mathrm{S} 1$, the longest segment, was installed in the direction that the tunnel leads, so for right-hand curves segment S1 would be placed on the left side of the segmental ring and vice versa for left-hand curves.

After the ring installation works were completed, the gap between the excavated ground surface and the extrados of the segmental ring was grouted using inert grout composed of lime and fly ash. At particular locations such as the break-in, break-out or at cross passage locations, active grout with cement content was used. This grouting operation was carried out concurrently with the TBM advance via grout lines within the TBM tail skin.

All the E\&M equipment of the TM-CLKL subsea tunnels was designed to be located underneath the carriageway. Therefore, a dedicated service gallery underneath the road deck was provided for operational personnel to access from the maintenance access paths at the ventilation shafts to the E\&M equipment housed underneath the road deck without disrupting tunnel traffic. The service gallery consists of an under carriageway ventilation duct (UCVD) and an E\&M ventilation duct (EMVD) as shown in Figure 13. The UCVD was designed to supply fresh air to the main tunnel carriageway through openings in the parapet and is fully isolated from other areas. The EMVD was designed to supply fresh air to the service corridor and extract smoke from the service corridor through damper openings in the event of fire. (a)

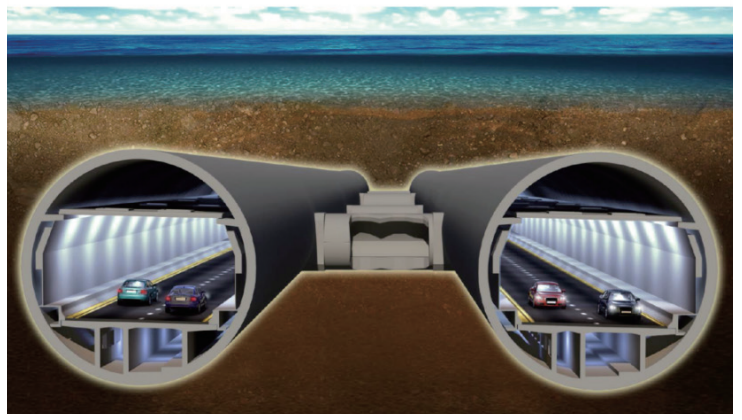

(b)

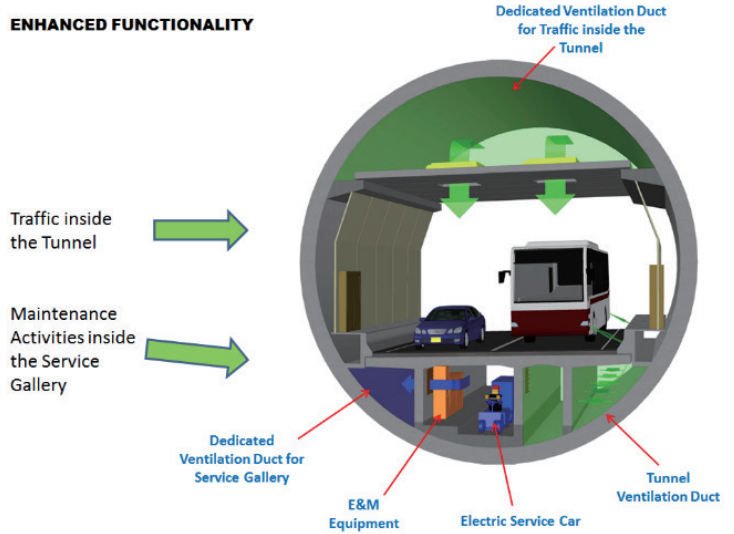

Figure 13. Typical arrangement of service gallery in sub-sea tunnel.

The service gallery is formed by a precast road deck element fabricated at an off-site precast yard. Other elements forming the internal structures of the sub-sea tunnels include the precast overhead ventilation duct (OHVD) slab which sits on corbels cast in-situ and the precast road barrier or parapet (Figure 14). A dedicated service gallery installation gantry (Figure 15), located behind the TBM, was designed to allow installation of these service gallery units whilst maintaining un-interrupted access for the TBM tunnelling logistics, such as delivery of precast lining segments and annulus grout material to the TBM. Similarly, a dedicated OHVD installation gantry (Figure 16) was designed to install the precast OHVD panels supported on the corbels cast in-situ whilst always maintaining free access for tunnel traffic. 


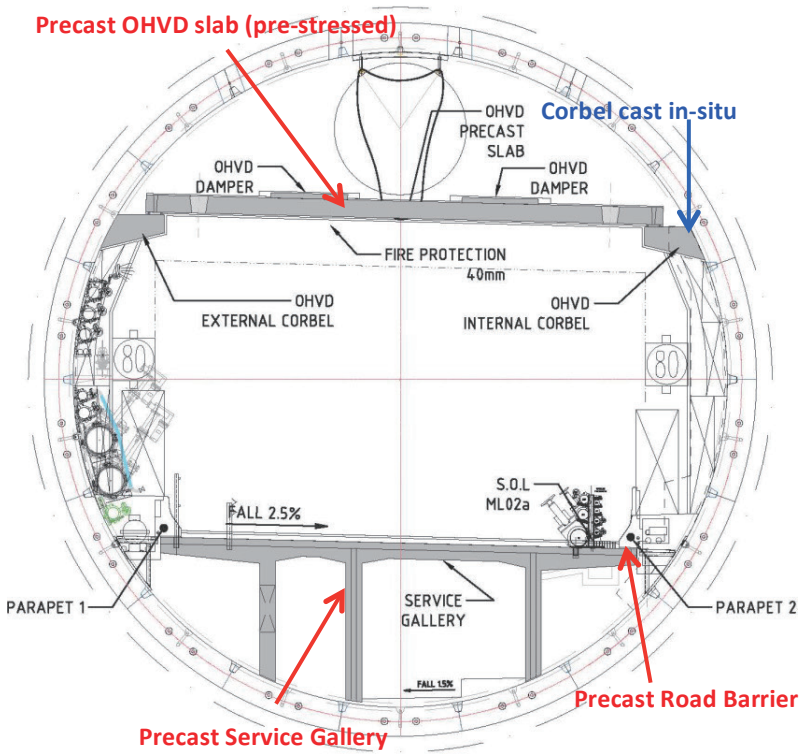

Figure 14. Typical arrangement of the sub-sea tunnel internal structures.

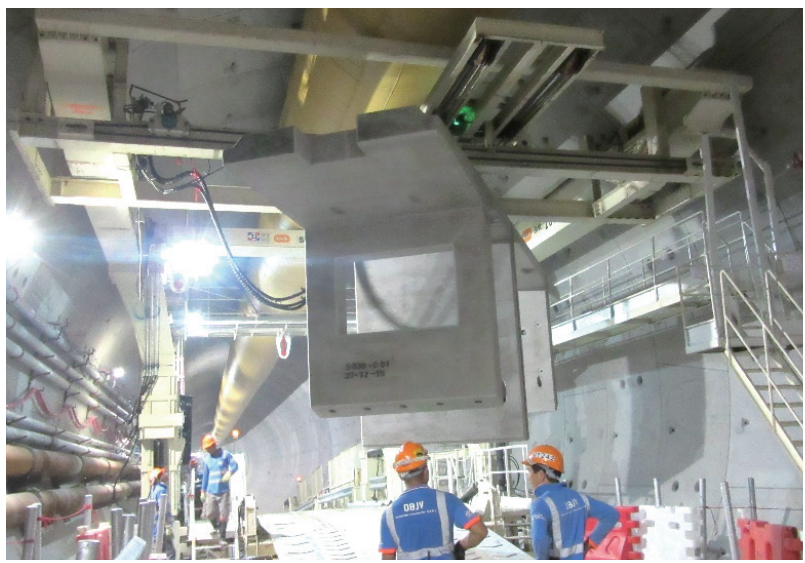

Figure 15. Service gallery installation.

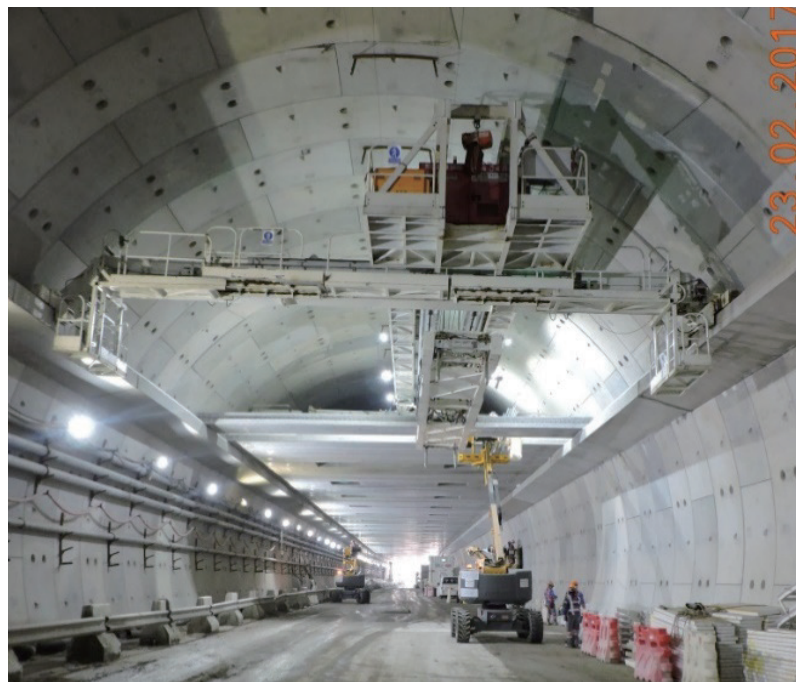

Figure 16. OHVD slab installation.

\section{Cross passage tunnelling by mini-TBM}

Between the two main tunnels, there were a total of 46 cross passages to be constructed in the sub-sea tunnel section at every $100 \mathrm{~m}$ interval. The average length of the cross passages was $13 \mathrm{~m}$. The cross passage construction was considered to be a potentially high-risk activity due to the high hydrostatic pressure. Ground freezing was initially proposed in the contract as the ground stabilisation method for the construction of cross passages in the sub-sea tunnel section. However, following extensive detailed technical reviews of the proposed ground freezing methodology, the design parameters of the frozen soil types were potentially lower (weaker strength) than the previously predicted values. Therefore, forming the substantial ice rings would require more drilling works and longer freezing times with an associated significant time implication to the contract. The contractor finally proposed, as an alternative design to the contract, pipe jacking method using a mini tunnel boring machine (MTBM) for the construction of cross passages in the sub-sea tunnel section.

The MTBM selected was a Herrenknecht slurry TBM. The advantages of using pipe jacking methodology were:

- It eliminates safety concerns associated with manual excavation;

- It can be used in almost all ground conditions under high water pressures;

- No ground treatment is required;

- No support arches or arch ribs are required in the main tunnels;

- It has minimum impact on internal structure installation;

- No pre-drilling through the permanent lining of the main tunnels is required; and

- It offers greater certainty in construction time.

The MTBM and the associated equipment were designed and developed by the contractor and the TBM supplier. This was the first project in the world in which cross passages were constructed by TBM pipe jacking methodology between two main tunnel tubes.

\subsection{Operation of the MTBM}

The MTBM selected for the cross passage excavation was designed to be capable of tunnelling through hard rock, but also suitable for excavating and supporting soft ground.

The excavation of cross passages was carried out after the erection of the main tunnel lining. The stress redistribution around the cross passage opening was taken up by six specially reinforced segments and by a concrete structural frame (tympanum) cast in-situ. Each main tunnel intersected the cross passage affecting three main tunnel segmental rings; one ring was entirely cut whilst the adjacent rings were partially cut. A soft eye using fibre glass reinforcement was provided to avoid damage to the cutterhead of the MTBM. The segments around this soft 
eye were reinforced with conventional steel reinforcement. The loads from the centre cut ring were effectively transferred to the adjacent rings either by shear keys or shear cones.

The four main hydraulic jacks of the jacking frame were connected to the tympanum on the launching side of the cross passage to be excavated. After final positioning of the frame, the gantry crane, located above the jacking trailer, lifted and transferred the MTBM cutterhead, interjacking stations and precast concrete pipes into the jacking position (Figure 17). During break-in and throughout the excavation stage, the waterproofing was guaranteed by two layers of $65 \mathrm{~mm}$ thick EPDM gaskets supplied by Trelleborg, forming the launching lip-seal. These seals were tested to 8.25 bar water pressure and the double layer provided $100 \%$ back-up or redundancy in the event that one seal failed. A mechanical emergency seal was also provided at the back of the launching seal to provide additional inundation prevention.

The MTBM excavation was carried out in short advances. The typical length of each jacking pipe was 1.33 $\mathrm{m}$. At each advance, a continuous circular concrete pipe was installed. On the receiving side, the MTBM would break-out to a pressurised steel bell (Figure 18). The main purpose of the steel bell was to maintain the pressurised regime in order to ensure that there was no sudden ingress of ground water or soil into the main tunnel during the MTBM break-out. The receiving bell was also equipped with an emergency seal in case of water ingress. The MTBM tunnelling set-up for cross passage construction is shown in Figure 19.

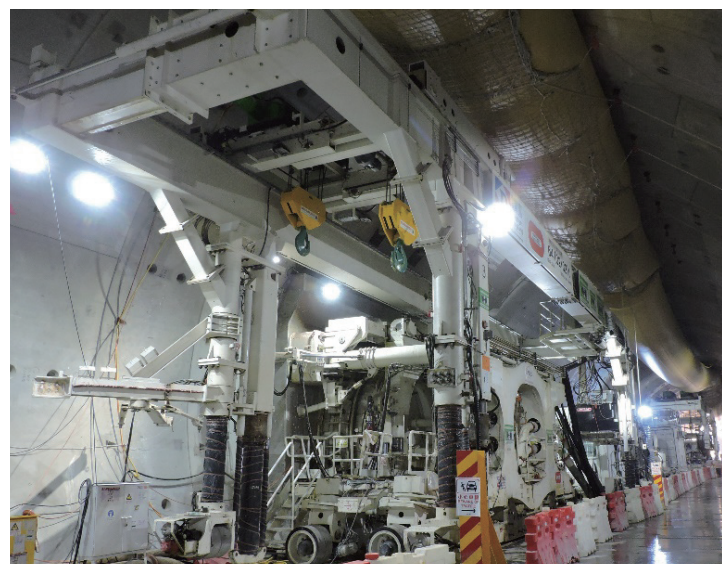

Figure 17. MTBM in jacking position.

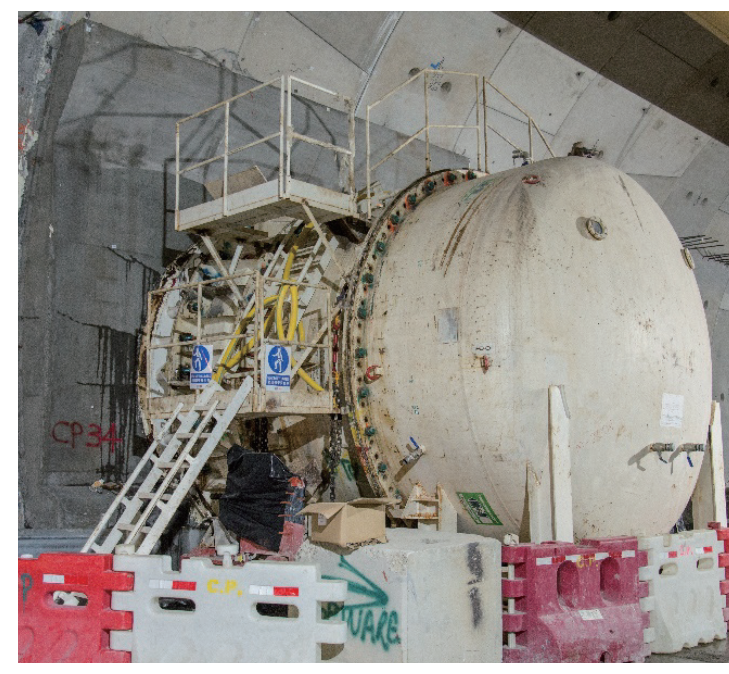

Figure 18. Receiving bell for MTBM break-out.

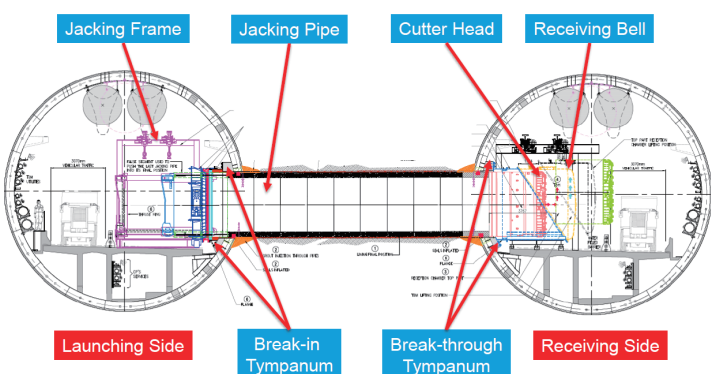

Figure 19. The MTBM tunnelling setup for cross passage construction.

\subsection{Pre-cast jacking pipe}

Permanent pre-cast reinforced concrete jacking pipes were used with the internal diameter of 3,000 mm. A typical cross section of the pre-cast reinforced concrete jacking pipes is shown in Figure 20.
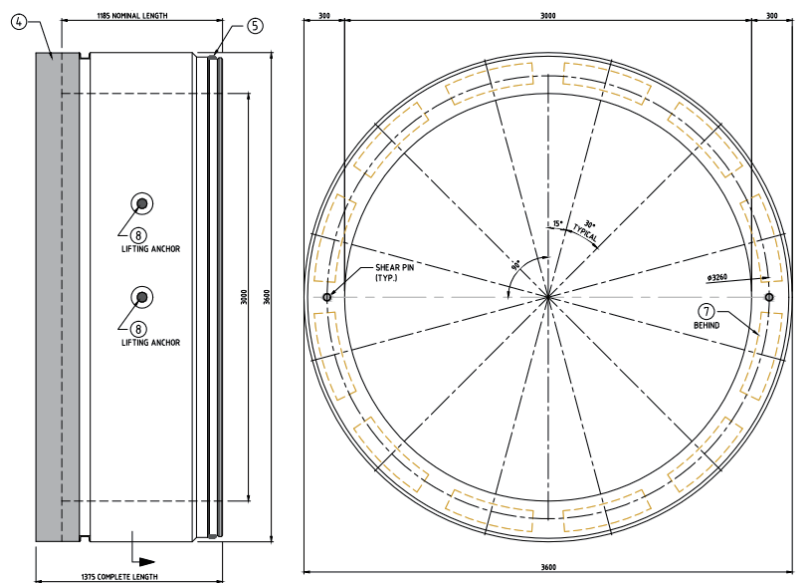

Figure 20. Typical cross section of precast concrete jacking pipe. 
The design of the pipe length was limited by the thrust cylinder stroke of the MTBM (1350 mm clearance distance). Six types of precast concrete jacking pipes were specially designed for the cross passages. They were known as first pipe, last pipe, standard pipe A, standard pipe B, lubrication pipe A and lubrication pipe B. The last pipe had the shortest length at $1,120 \mathrm{~mm}$, while standard pipe A and lubrication pipe A had the longest length at $1,330 \mathrm{~mm}$.

A double water barrier concept was adopted for each pipe connection to ensure long-term water tightness. The thickness of the steel collar was $25 \mathrm{~mm}$ at each segment joint to ensure a design life of 120 years against corrosion.

The contact faces between jacking pipes were equipped with wooden packers in order to minimise the risk of concrete bursting during the load transfer of the pipe jacking operation. The machine torque was resisted by shear pins placed between two reinforced concrete jacking pipes. The pins helped prevent the MTBM and the jacking pipes from self-rotation. Guiding bars were also installed, passing through the whole length of the jacking pipes, providing sufficient steering resistance to the MTBM.

The actions induced by the pipe jacking machine ram loads were imposed at the circumferential edge of the pipes. The design of the pipes took into account both bursting stress underneath the ram shoes and tensile stress between the ram shoes.

\section{Tunnelling performance overview}

TBM tunnelling was carried out round the clock in two shifts of 12 hours, seven days per week. The utilisation rate (i.e. the duration of TBM advance and ring build) of the $17.6 \mathrm{~m}$ diameter TBM (S880) was 35\%. As TBM (S880) was the first TBM to launch in the LS, the utilisation rate was affected by the learning curve of the TBM and the start-up of all the associated TBM support logistics such as the STP, slurry feed lines, annulus grout plant, etc.

In contrast, the utilisation rate of the $14 \mathrm{~m}$ diameter TBMs (S881 and S882) was 43\%, which was comparatively higher than that of the TBM (S880) as there was no learning curve associated with the operation of these sub-sea TBMs after the first one TBM (S880) had been launched.

For tunnelling in the northern approach tunnel from the north LS to the NVS through newly reclaimed ground, and soft alluvium/weaker CDG, TBM (S880) advanced at an average of $3.3 \mathrm{~m} /$ day with a best record of $10 \mathrm{~m}$ in one day, whereas TBM (S882) in the northern approach tunnel advanced at an average of $4.7 \mathrm{~m} /$ day with a best record of $12.8 \mathrm{~m}$ in one day. Only minor settlement was recorded on the ground surface across this zone with a volume face loss of less than $1.3 \%$, which is below the specification of $2 \%$ (Kwong et al., 2019).

TBMs S881 and S882 have better performance records in the tunnelling of the sub-sea tunnel section. Both
TBMs achieved an average advance of $10 \mathrm{~m} /$ day with a best record of $29 \mathrm{~m}$ in one day (Chan and Kwong, 2019). The volume loss of the sub-sea section was unavailable since it was not possible to carry out settlement monitoring of the seabed except in the zone of the electric power submarine cables, where echo sounding surveys were carried out before and after the transit of the TBMs through the electric power cable protection zone, and indicated no abnormal settlement of the cables.

Comparing the TBM advance rate between the northern approach tunnel and the sub-sea tunnel section, the lower TBM advance rate for the northern approach tunnel was expected due to the learning curve, waiting for removal of surcharge on the newly reclaimed land, completion of ground treatment works ahead of the TBM tunnelling and the timing of the completion of the NVS at the NLF.

As for the hyperbaric interventions, over 930 sessions of intervention under pressure between 2.9 bar - 5.78 bar were conducted, of which a total of 18 saturation cycles were conducted for the construction of TM-CLKL sub-sea tunnels with more than 1,200 disc cutters changed on the two TBMs. There were zero cases of decompression illness reported.

Cross passage construction involved a number of works activities such as tympanum construction, mobilisation of MTBM, MTBM excavation, grouting and demobilisation of the MTBM upon completion of each cross passage and re-mobilisation to the next one. The process for mobilisation of the MTBM was the most time consuming activity. The contractor focused on the resources for mobilisation and implemented 24-hour, 7-days-a-week uninterrupted resources for mobilisation of the MTBM. Over the whole period of cross passage construction, the MTBM excavation cycle was reduced from 28 days to 18 days. The MTBM generally performed very well in each cross passage drive despite the different geological profiles. The average advance rate of the MTBM was $2.3 \mathrm{~m} /$ day with a best record of $13.2 \mathrm{~m}$ in one day.

The construction of mechanised cross passages was carried out progressively from the NLF towards the south. This provided a learning period for the contractor to develop the new pipe jacking TBM methodology and an opportunity to optimise the construction sequence for the subsequent sub-sea cross passages. The ground settlement associated with the target volume loss of the completed cross passages was evaluated from the field measurements. The results demonstrated that the excavation of cross passages using the mechanised method was possible without causing unacceptable ground movement.

There were no compressed air interventions conducted for cutterhead maintenance on the MTBM during the excavation of the cross passages as the contractor adopted a strategy of thoroughly inspecting the cutterhead and replacing all the worn disc cutters during the remobilisation period and before commencing a new cross passage construction. 


\section{Challenges}

\subsection{TBM cutterhead interventions in complicated ground conditions by ground freezing}

The TBM for the southbound tunnel came to a halt at the cross passage (CP8) location, which was $57 \mathrm{~m}$ before the TBM breakthrough location at the SVS of the SLF. The TBM was not able to excavate further when it encountered concrete barrettes installed at the cross passage location by the contractor, because of excessively worn cutters (Figure 21).

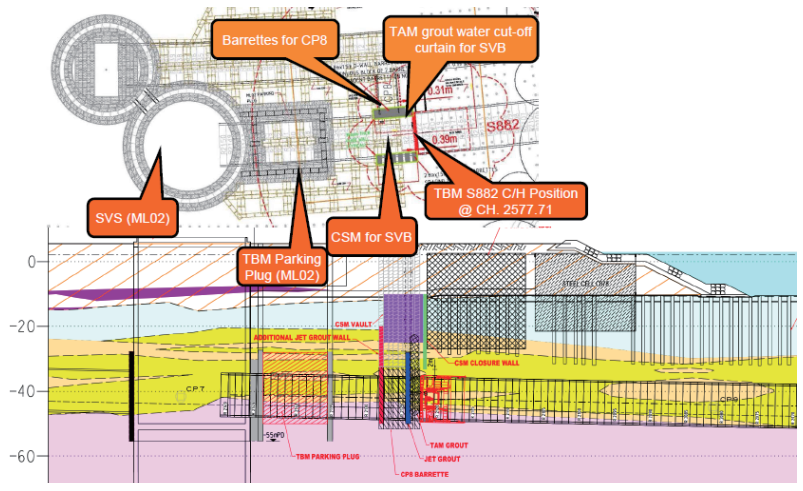

Figure 21. Disturbed ground at CP8 location.

No interventions had been conducted on the TBM to inspect or change the disc cutters for over $800 \mathrm{~m}$ during the last section of the sub-sea tunnel construction due to unfavourable geology incorporating alluvial sand layers, through which there was a risk of excessive air loss during intervention. The disc cutters had therefore been subjected to a substantial degree of wear and tear. In addition, when the TBM encountered the artificial obstruction (i.e. the concrete barrettes), the disc cutters may have been subjected to impact damage upon initial contact. The damaged or worn cutters were required to be replaced with new cutters before the TBM could resume excavation. Hyperbaric interventions were therefore required to be conducted in the prevailing unfavourable ground conditions.
Intervention in these unfavourable ground conditions was challenging as instability of the face or the crown would endanger the compressed air workers inside the working chamber. The existing soft ground had been further disturbed during the construction of the barrettes at $\mathrm{CP} 8$ which were required to strengthen the main tunnel connection at CP8 in the southbound tunnel. In addition to the barrettes, the area had also been disturbed by the construction of a Tube-à-Manchette (TAM) grout water cutoff curtain and cutter soil mixing (CSM) ground treatment for the foundation of the south ventilation building (Figure 21). Some form of ground treatment was therefore required to improve or stabilise the ground in order to ensure that TBM interventions could be carried out safely.

Different ground treatment methods were proposed and implemented in order to stabilise the ground at the crown of the TBM. These included a jet grout curtain, CSM grout block and compaction grouting. Upon implementation of these different ground treatment works, attempts to carry out interventions were made but in each case failed and the attempts had to be aborted for safety reasons.

Ground freezing using liquid nitrogen was then considered to freeze the ground in order to stabilise the excavated face of the TBM before any further interventions.

After the ice block was formed, TBM interventions were able to be conducted to change all the damaged disc cutters and cutting tools. Despite constraints associated with the tidal effect of groundwater, and the circulation of slurry refill inside the TBM excavation chamber affecting the cooling efficiency of the original ice block design, these constraints were overcome through regular design review and improvements on the TBM intervention procedure. The freeze was able to be maintained in a stable condition long enough for all the cutter discs and the cutting tools to be replaced before the TBM was restarted and successfully completed the sub-sea southbound tunnel.

\subsection{TBM tunnelling in newly reclaimed land}

The TBMs were designed to launch in a LS located at a strip of newly reclaimed land $1 \mathrm{~km}$ in length at the NLF just east of the RTT.

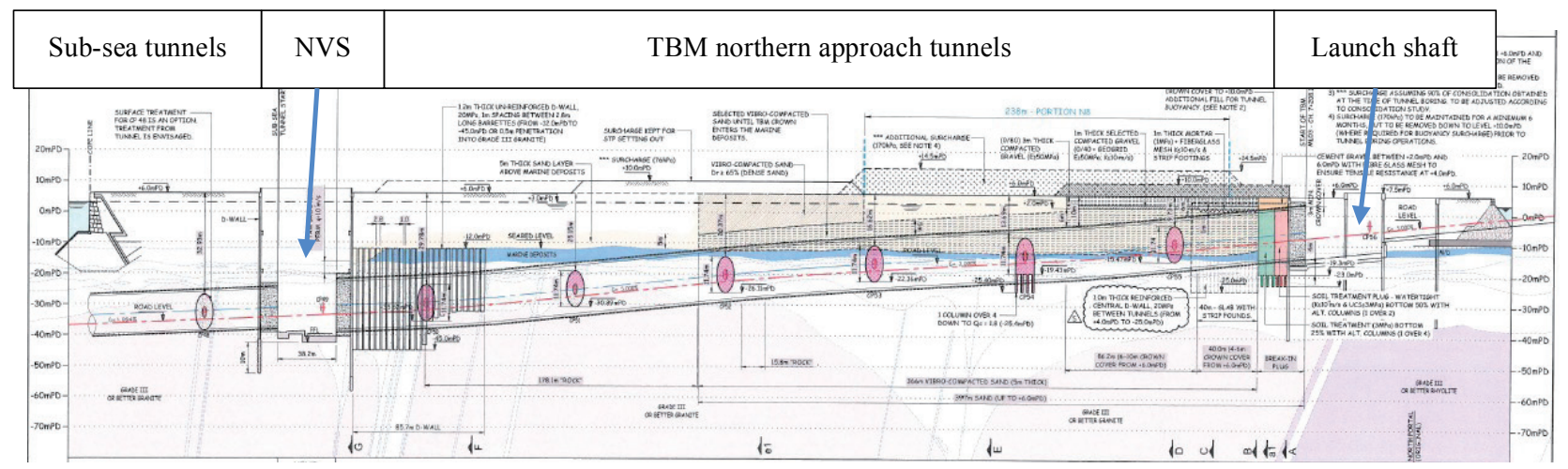

Figure 22. Ground treatment at the NLF. 


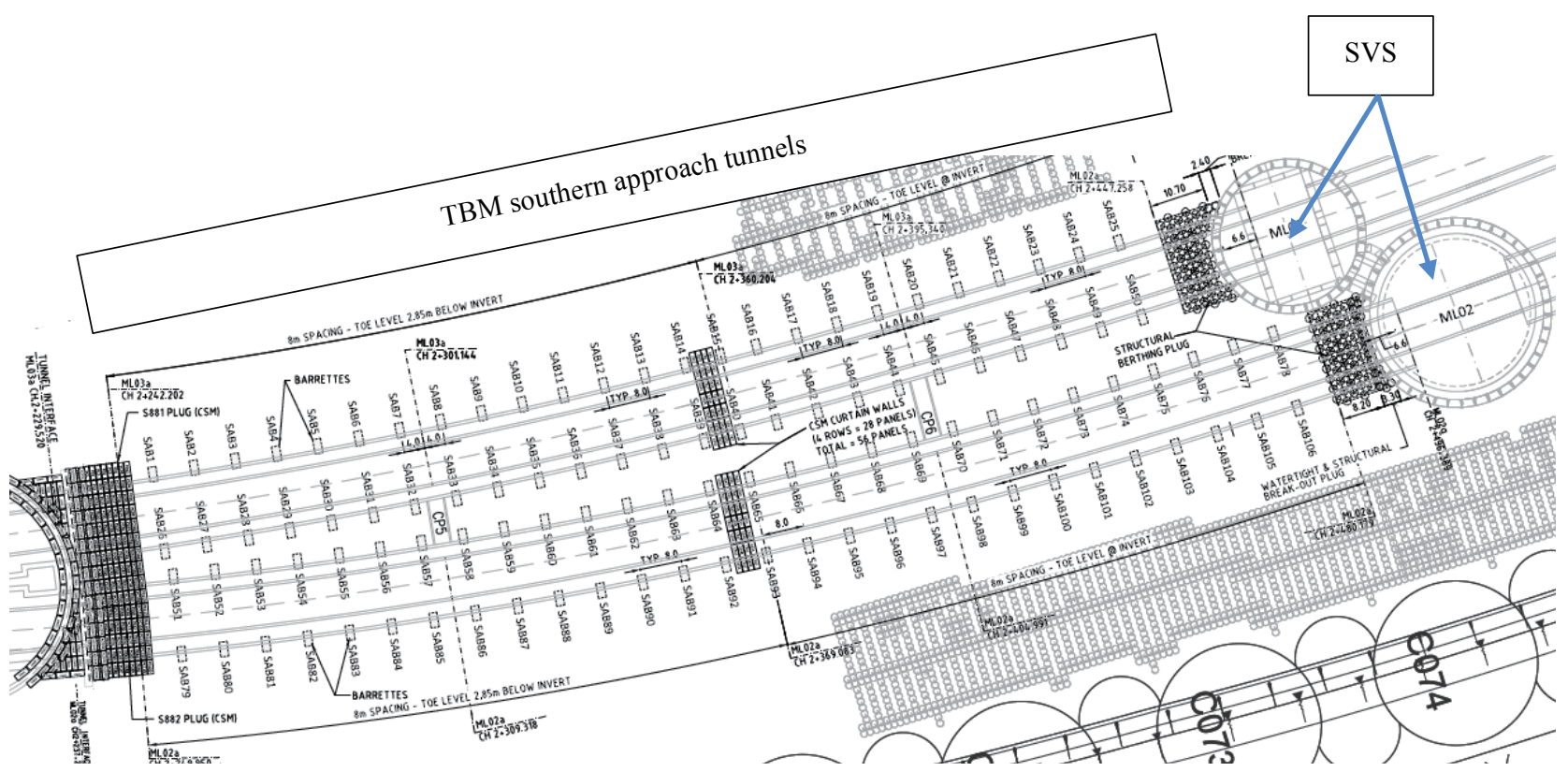

Figure 23. Ground treatment at the SLF.

Tunnelling in newly reclaimed land poses a risk of lining ovalisation and instability resulting from continuous settlement/consolidation of the land. In order to accelerate the consolidation of the newly reclaimed land, different ground treatment methods were used between the LS of the TBMs and the NVS (Figure 22) (Kwong et al., 2018).

Prior to TBM tunnelling, band drains with surcharge were applied to limit the residual settlement to less than 500 $\mathrm{mm}$ and the differential settlement of the reclaimed land to 1 in 300. In addition, deep vibro-compaction was carried out at the sand fill and surcharging above final formation level to reduce the residual and secondary settlements of the soft marine deposits which remained underneath the reclamation.

Other ground treatment works required for TBM tunnelling included the formation of a break-in plug at the LS using the CSM method and jet grouting columns; and formation of jet-grouted separation walls parallel to both tunnel sidewalls outside the break-in plug of the LS due to close separation of the tunnel tubes and break-out plug at the NVS.

After the sub-sea tunnel section, there was a section of approximately 250-metre-long TBM southern approach tunnels to be constructed in the SLF before the TBM finally broke out at the caterpillar shaft built for the construction of the cut-and-cover tunnels. Unlike the NLF, the SLF was a new reclamation formed by others which was still undergoing consolidation at the time of hand-over to this contract. Again, tunnelling in newly reclaimed land poses a risk of lining ovalisation and instability resulting from continuous settlement/consolidation of the land. In order to ensure long-term structural integrity of the TBM tunnels and minimise the long term ovalisation of the future tunnels, a total of 106 unreinforced barrette panels were constructed along both sides of the future tunnel tubes prior to TBM tunnelling.

Other ground treatment works required for TBM tunnelling included the formation of a break-out plug at the caterpillar shaft using CSM and reinforced diaphragm wall panels to stabilise the ground and improve the water impermeability, hence minimising ground water ingress during the TBM breakthrough. (Figure 23)

\section{Conclusion}

The challenges for the construction of the TM-CLKL tunnels included:

- $\quad$ sub-sea tunnelling up to $55 \mathrm{~m}$ below sea level in mixed ground geology that required replacement of TBM cutting tools at hyperbaric pressure up to 5.8 bar;

- replacement of worn TBM cutting tools in complicated ground conditions;

- construction of approach tunnels in newly reclaimed land subject to long-term consolidation;

- construction of cross passages at $100 \mathrm{~m}$ intervals between the two sub-sea tunnels with a risk of sea water ingress at 5.5 bar.

A number of sophisticated techniques were deployed to tackle the challenges encountered during the construction of the TM-CLKL sub-sea tunnels.

First of all, the world's largest Mixshield TBM was successfully launched for the excavation of the northern approach tunnel. The TBMs were tailor-made and equipped with innovative equipment to minimise 
the number of manned interventions required during the sub-sea tunnelling. Saturation diving techniques were successfully implemented for manned interventions up to 5.8 bar with zero cases of decompression illness. Despite having a comprehensive intervention strategy for disc cutter maintenance, the TBM became stuck at CP8, where ground freezing using liquid nitrogen was deployed to create a safe haven for TBM interventions to change the worn cutting tools at the cutterhead successfully.

In addition to having sophisticated tunnelling machines, different ground treatment methods were designed to accelerate the consolidation of the newly reclaimed land and/or to assure the structural stability of the segmental lining over the long period of ground consolidation.

Aside from the main sub-sea tunnels, the construction of the cross passages by mini-TBM that was successfully implemented in the TM-CLKL sub-sea tunnel project was a major pioneering breakthrough in construction methodologies that will resonate throughout the global tunnelling industry.

\section{Acknowledgements}

The authors are grateful for the support from the Highways Department, HKSARG. However, the contents of this paper do not necessarily reflect the views and policies of these supporting organisations, nor does the mention of trade names and commercial products constitute endorsement or recommendations for use.

\section{Notes of contributors}

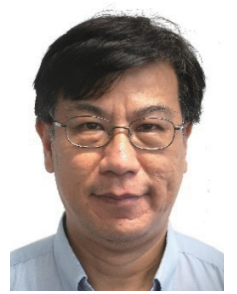

Ir Albert W Y Chan received his B.Sc. and M.Sc. degree in Civil Engineering from The University of Hong Kong in 1988 and 1996 respectively. He has more than 30 years of experience in delivering civil works projects in Hong Kong. For tunnel projects, he was involved in the Harbour Area Treatment Scheme Stage 1 and Stage $2 \mathrm{~A}$ as well as the Tsuen Wan Drainage Tunnel project.

Albert is currently Chief Engineer of the East Development Office, Civil Engineering and Development Department. He was Senior Engineer in the Major Works Project Management Office (Special Duties) of the Highways Department managing the Tuen Mun-Chek Lap Kok Link project including the construction of the sub-sea tunnel until its completion.

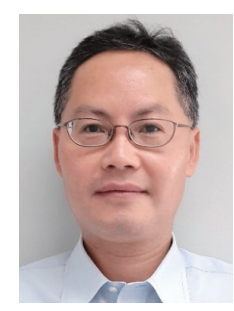

Ir Charles H C Yeung received his B.Sc. degree in Civil Engineering from The University of Hong Kong in 1988 and diplôme d'ingénieur from L'Ecole Nationale des Travaux Publics de l'Etat in France in 1990 respectively. He has more than 30 years of experience in tunnel projects involving drill and blast, and TBM. The tunnel projects he has been involved include Route 3 Tai Lam Tunnel, KCR West Rail Tai Lam Tunnel, KCR Lok Ma Chau Spur Line, MTR Kowloon Southern Link, MTR Express Rail Link, Tuen Mun-Chek Lap Kok Link Northern Connection Sub-sea Tunnel Section.

Charles is currently Senior Resident Engineer (Tunnel) in Hyder-Meinhardt JV supervising the Contract of Trunk Road T2 sub-sea tunnels. He was Senior Resident Engineer (TBM) in AECOM between 3 December 2013 and 31 December 2019 supervising the Contract of the Tuen MunChek Lap Kok Link Northern Connection Sub-sea Tunnel Section.

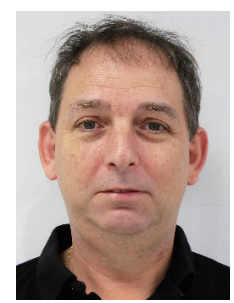

Ir Andy $\mathbf{J}$ Westmoreland has more than 35 years of experience in the tunnelling industry, starting with the Singapore MRT in 1983, the Channel Tunnel Project in 1988 and the Storebaelt Project in Denmark in 1991 before settling in Hong Kong in 1995. In Hong Kong, he has been involved in a number of major tunnelling projects and the development of hyperbaric tunnelling. Andy was Chief Resident Engineer (TBM) for AECOM between 30 August 2013 and 31 December 2019 supervising the Contract of the Tuen Mun-Chek Lap Kok Link Northern Connection Sub-sea Tunnel Section and is currently in a similar role for Hyder- Meinhardt JV on the T2 Trunk Road Sub-Sea Tunnel Project.

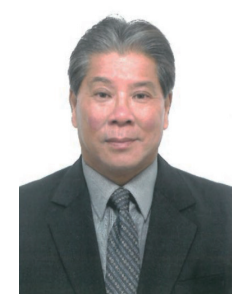

Ir S W Fok obtained his B.Sc. and BA degrees. He has 43-year solid construction experience in Hong Kong involving in an extremely wide range of both marine and land-based structures including bridges, viaducts, roads, drains, and hightech buildings. He also has extensive experience in TBM tunnelling, marine reclamation, site formation blasting and heavy foundations, i.e. bored piling, rock socket H-piles, diaphragm walling, top down construction and deep excavation for tunnelling and basement structures. He is Principal Resident Engineer of AECOM supervising the construction phase of the Tuen Mun-Chek Lap Kok Link project. 


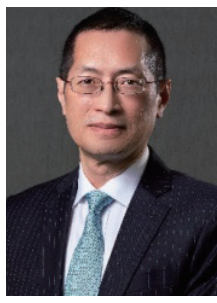

Ir Conrad C W Ng received his B.Sc. degree in Civil Engineering from The University of Hong Kong in 1982. He is currently Vice President of AECOM who has over 38 years of local experience in planning and feasibility study, design and documentation, project management, and construction and contract administration of various highway and tunnel infrastructure and major multi-disciplinary projects including Tseung Kwan O Tunnel, Route 8 between Cheung Sha Wan and Sha Tin, Central-Wan Chai Bypass and Island Eastern Corridor Link, Tuen Mun-Chek Lap Kok Link, Tseung Kwan O-Lam Tin Tunnel, Cross Bay Link, and Lok Ma Chau Loop.

Mr Fabrice Guedon was Project Director of DragagesBouygues Joint Venture, the Contractor for the Contract of the Tuen Mun-Chek Lap Kok Link Northern Connection Sub-sea Tunnel Section between 23 January 2017 and 10 July 2019.

\section{References}

[1] Tracking the world's mega-TBMs (2020). TunnelTalk discussion forum. September 2020. Available at: $<$ https://www.tunneltalk.com/Discussion-ForumTracking-the-mega-TBMs-of-the-world.php>. [Accessed on 20 September 2021].

[2] Chan AWY, Yeung CHC, Westmoreland AJ, Fok SW, $\mathrm{Ng} \mathrm{CCW}$ and Guedon F (2021). Use of Saturation Diving Technique for TBM Cutterhead Intervention in the TM-CLKL Sub-sea Tunnel Project, Hong Kong. HKIE Transactions, 28(1), pp. 31-38.

[3] Kwong, AKL, Ng, CCW and Schwob, A (2018). Ground Treatment in a Reclaimed Land for Launching of the Subsea Tunnel Boring Machine under the Tuen Mun-Chek Lap Kok Link Project, Hong Kong. Annual Geotechnical Seminar, The Hong Kong Institution of Engineers, May, Hong Kong.

[4] Kwong, AKL, Ng, CCW, and Schwob, A (2019). Control of Settlement and Volume Loss Induced by Tunnelling under a Recently Reclaimed Land. International Journal of Underground Space, 4(4), pp. 289-301.

[5] Chan, KLL, and Kwong, AKL (2019). Geotechnical Risks, Mitigation Measures, and Performance of TBM Tunnels for the Tuen Mun-Chek Lap Kok Link Project, Hong Kong. HKIE Transactions, 26(4), pp.175-189. 